\title{
Clinical Outcomes of Patients Hospitalized with Coronavirus Disease 2019 (COVID-19) in Boston
}

\author{
Areej El-Jawahri, MD ${ }^{1,2}$ (D) , Hacho B. Bohossian, MD ${ }^{3,4}$, \\ Michael K. Paasche-Orlow, MD, MA ${ }^{5,6}$, Joshua R. Lakin, $M D^{2,7}$, \\ P. Connor Johnson, $M D^{1,2}$, Zara Cooper, $M D^{2,8}$, Annemarie D. Jagielo, $B A^{7}$, \\ Elise N. Brannen, $B A^{2,8}$, Matthew J. Reynolds, $B A^{2}$, Kathleen Coogan, $B S^{8}$, \\ Dagny Vaughn, $B A^{7}$, and Angelo Volandes, $M D, M P H^{1,2,3,9}$
}

'Department of Hematology Oncology, Massachusetts General Hospital, Boston, MA, USA; ${ }^{2}$ Harvard Medical School, Boston, MA, USA; ${ }^{3}$ NewtonWellesley Hospital, Newton, MA, USA; ${ }^{4}$ Tufts University School of Medicine, Boston, MA, USA; ${ }^{5}$ Boston Medical Center, Boston, MA, USA; ${ }^{6}$ Boston University School of Medicine, Boston, MA, USA; ${ }^{7}$ Dana Farber Cancer Institute, Boston, MA, USA; ${ }^{8}$ Brigham and Women's Hospital, Boston, MA, USA; ${ }^{9}$ Advance Care Planning (ACP) Decisions, Newton, MA, USA.

BACKGROUND: Outcomes of hospitalized patients with COVID-19 have been described in health systems overwhelmed with a surge of cases. However, studies examining outcomes of patients admitted to hospitals not in crisis are lacking.

OBJECTIVE: To describe clinical characteristic and outcomes of all patients with COVID-19 who are admitted to hospitals not in crisis, and factors associated with mortality in this population.

DESIGN: A retrospective analysis

PARTICIPANTS: In total, 470 consecutive patients with COVID-19 requiring hospitalization in one health system in Boston from January 1, 2020 to April 15, 2020.

MAIN MEASURES: We collected clinical outcomes during hospitalization including intensive care unit (ICU) admission, receipt of mechanical ventilation, and vasopressors. We utilized multivariable logistic regression models to examine factors associated with mortality.

KEY RESULTS: A total of 470 patients (median age 66 [range 23-98], 54.0\% male) were included. The most common comorbidities were diabetes $(38.5 \%, 181 / 470)$ and obesity (41.3\%, 194/470). On admission, 41.9\% (197/ 470) of patients were febrile and $60.6 \%$ (285/470) required supplemental oxygen. During hospitalization, $37.9 \%$ (178/470) were admitted to the ICU, 33.6\% (158/ 470) received mechanical ventilation, 29.4\% (138/470) received vasopressors, $16.4 \%(77 / 470)$ reported limitations on their desire for life-sustaining therapies such as intubation and cardiopulmonary resuscitation, and $25.1 \%(118 / 470)$ died. Among those admitted to the ICU $(N=178)$, the median number of days on the ventilator was 10 days (IQR $1-29)$, and 58.4\% (104/178) were discharged alive. Older age $(\mathrm{OR}=1.04, P<0.001)$, male sex $(\mathrm{OR}=2.14, \mathrm{P}=0.007)$, higher comorbidities $(\mathrm{OR}=1.20$, $P=0.001$ ), higher lactate dehydrogenase on admission (2nd tertile: $\mathrm{OR}=4.07, P<0.001$; 3rd tertile: $\mathrm{OR}=8.04$, $P<0.001$ ), and the need for supplemental oxygen on admission (OR=2.17, $P=0.014)$ were all associated with higher mortality.

Received June 6, 2020

Accepted January 14, 2021

Published online February 24, 2021
CONCLUSIONS: The majority of hospitalized patients with COVID-19 and those who received mechanical ventilation survived. These data highlight the need to examine public health and system factors that contribute to improved outcomes for this population.

J Gen Intern Med 36(5):1285-91

DOI: $10.1007 /$ s11606-021-06622-x

(C) Society of General Internal Medicine 2021

\section{INTRODUCTION}

The novel coronavirus disease 2019 (COVID-19) pandemic has infected millions of people worldwide, leading to a surge in hospital utilization. ${ }^{1-3}$ Although most patients with COVID-19 have a favorable prognosis, COVID-19 may result in critical illness requiring intensive interventions such as ventilatory support, especially in older patients and those with underlying serious comorbid conditions. ${ }^{3,4}$ To meet these needs, health systems and hospitals have had to rapidly reorganize in-patient services and expand ICU capacity. An accurate representation of clinical outcomes for people hospitalized with COVID-19 can improve planning for health systems, hospitals, clinicians, and patients.

Among patients admitted to hospitals, key parameters include the portion that will need ICU level care and ventilatory support, the length of time people would need such services, and the mortality rate. To date, much of the data for such factors has come from health systems in China, Italy, and New York that endured critical shortages of services. ${ }^{3-7}$ Accordingly, in prior reports, it can be hard to differentiate the impact of COVID-19 from the influence of overwhelmed capacity.

A clear understanding of outcomes is also extremely important for advance care planning (ACP). ACP is a shared decision-making process in which patients and clinicians weigh the risks and benefits of such interventions in the context of the patient's values and preferences. ${ }^{8,9}$ The intent of ACP remains unchanged during times of a 
pandemic - aligning medical care delivery with patient preferences. ${ }^{8-10}$ However, extrapolating data from health systems in crisis, where the demand for care far outpaced the supply, is problematic for clinicians who are working to make individual patient decisions.

We sought to report the clinical characteristics and factors associated with ventilatory support, survival, and discharge disposition for all COVID-19 patients admitted to hospitals that are not in crisis, but where COVID-19 disease burden was high and in a surge state, a critically important situation that is unique from prior studies and reports of COVID-19 outcomes. We present a retrospective analysis from a large health care system in the Boston metropolitan region. Although considered an early hotspot for COVID-19, Boston did not surpass capacity or initiate crisis standards.

\section{METHODS}

\section{Study Design}

This study was approved by the Partners Institutional Review Board. We conducted a retrospective analysis of all patients hospitalized with confirmed diagnoses of COVID-19 treated at Partners hospitals between January 1, 2020 and April 15, 2020. We used the Partners HealthCare Research Patient Data Registry (RPDR) which stores clinical data for 6.5 million individuals who receive their care from Partners HealthCare providers in Massachusetts. Partners HealthCare provides care in academic, community hospitals, and rehabilitation networks across New England. Partners HealthCare has emergency services integrated across most of its member institutions and includes over 200 ICU beds. We included patients admitted to 5 academic and community hospitals within Partners HealthCare in this study. We used COVID-19 diagnoses codes to identify patients hospitalized with COVID-19, which we confirmed by manual chart review. Partners hospitals did not utilize strict criteria for hospital admission. Instead, the decision regarding the need for hospital admission was left at the discretion of the treating physician. All patients with a positive nasopharyngeal polymerase chain reaction test were included. Clinical outcomes were monitored until May 11, 2020. Patients who were still hospitalized by May 11, 2020, were excluded from analyses. Transfers from one hospital to another were merged and considered a single visit. For patients with a readmission during the study period, data from multiple admissions were merged and considered a single visit.

\section{Demographic and Clinical Characteristics}

We conducted a comprehensive chart review to obtain information regarding patients' demographics, comorbidities, home medications, and laboratory findings. We collected race and ethnicity using the electronic health record (EHR) prespecified fixed categories. We obtained data on home medications based on the admission medication reconciliation record. We used the Charlson Comorbidity Index (CCI) to examine comorbid conditions as documented in the EHR. ${ }^{11}$ We also collected data on the use of certain therapies during hospitalization including corticosteroids, hydroxychloroquine, remdesivir, and tocilizumab.

\section{Clinical Outcomes}

We obtained information regarding hospital length of stay (LOS), ICU admission, and the need for mechanical ventilation, vasopressors, renal replacement therapy, and extracorporeal membrane oxygenation (ECMO) from the electronic medical record. We also collected data on palliative care consultation, code status at the time of admission to the hospital and any changes to code status throughout the hospitalization using EHR order entry. We also collected vital status (discharged alive or dead) as well as discharge disposition. To ensure data fidelity, two coders independently reviewed $10 \%$ of all hospitalization outcome data and achieved excellent reliability (97\% agreement).

\section{Statistical Analysis}

We used descriptive statistics including frequencies and percentage for categorical variables and means \pm standard deviations (SD) for continuous variables to summarize participant characteristics and clinical outcomes. All reported $P$ values were two-sided, with $P<0.05$ considered statistically significant.

We conducted unadjusted analyses examining the association between demographic and clinical factors of interest with mortality. The following factors were considered in the unadjusted analyses: demographics (age, sex, race (White vs. all other racial categories), and ethnicity), home medications (statins, non-steroidal anti-inflammatory drugs, corticosteroids, angiotensin-converting enzyme inhibitors, or angiotensin II receptor blockers), history of smoking, obesity, comorbidities (CCI), the need for supplemental oxygen on admission, inflammatory markers (lactate dehydrogenase, Creactive protein, ferritin, and D-dimer), and treatments (remdesivir, corticosteroids, or hydroxychloroquine). Factors that were associated with mortality with a $P$ value $<0.10$ were then included in the multivariate logistic regression model, as recommended by literature on logistic regression model building. ${ }^{12-14}$ Given collinearity between inflammatory markers, only lactate dehydrogenase was included in the final multivariable logistic regression model.

\section{RESULTS}

\section{Patient Characteristics}

Table 1 depicts the clinical characteristics of all patients $(N=470)$ included in this analysis. The median age of the cohort was 66.0 (range 23-98). Overall, 254 patients 
were male (54.0\%) and 286 were non-Hispanic (60.9\%) and the plurality were White $(200 / 470,42.6 \%)$. Most patients were living at home prior to admission (73.4\%, $345 / 470)$, and $86(18.3 \%)$ were admitted from a skilled nursing facility. The most common comorbidities were obesity $(41.3 \%, 194 / 470)$, diabetes $(38.5 \%, 181 / 470)$, cancer $(18.1 \%, 85 / 470)$, congestive heart failure $(14.5 \%, 68 / 470)$, and dementia $(14.0 \%, 66 / 470)$. The median CCI score was 4 (range 0-14).

Two hundred eighty-five patients required supplemental oxygen at the time of admission (60.6\%) and 197 (41.9\%) were febrile on admission. Inflammatory markers at the time of admission are presented in Table 2. Most patients were "full code" with no restrictions on life-sustaining treatments at the time of admission $(83.6 \%, 393 / 470)$.

Overall, 91 patients remained hospitalized by May 11, 2020, and were excluded from the analyses. Among those who remained hospitalized, $50.6 \%$ (46/91) were admitted to the ICU, but only $16.5 \%$ (15/91) remained in the ICU at the time of last follow-up.

Table 1 Baseline Characteristics of Patients Hospitalized with COVID-19. $A C E-I$, angiotensin-converting enzyme inhibitor; $A R B$, angiotensin receptor blocker; $B M I$, body mass index

\begin{tabular}{|c|c|}
\hline Baseline characteristics & $\begin{array}{l}\text { Total cohort }(N= \\
\text { 470) }\end{array}$ \\
\hline Age, median (range) & $66.0(23-98)$ \\
\hline \multicolumn{2}{|l|}{ Sex, $N(\%)$} \\
\hline Male & $254(54.0 \%)$ \\
\hline Female & $216(46.0 \%)$ \\
\hline \multicolumn{2}{|l|}{ Race, $N(\%)$} \\
\hline White & $200(42.6 \%)$ \\
\hline Black & $110(23.4 \%)$ \\
\hline Asian & $13(2.8 \%)$ \\
\hline American Indian & $1(0.2 \%)$ \\
\hline Other & $137(29.1 \%)$ \\
\hline Missing & $9(1.9 \%)$ \\
\hline \multicolumn{2}{|l|}{ Ethnicity, $N(\%)$} \\
\hline Hispanic & $174(37.0 \%)$ \\
\hline Non-Hispanic & $286(60.9 \%)$ \\
\hline Missing & $10(2.1 \%)$ \\
\hline \multicolumn{2}{|l|}{ Living situation, $N(\%)$} \\
\hline Home & $345(73.4 \%)$ \\
\hline Skilled nursing facility & $86(18.3 \%)$ \\
\hline Other & $29(6.2 \%)$ \\
\hline Missing & $10(2.1 \%)$ \\
\hline History of statin use, $N(\%)$ & $230(48.9 \%)$ \\
\hline History of ACE-I/ARB use, $N(\%)$ & $149(31.7 \%)$ \\
\hline \multicolumn{2}{|l|}{ Comorbidities, $N(\%)$} \\
\hline Diabetes & $181(38.5 \%)$ \\
\hline Prior smoking history & $186(39.6 \%)$ \\
\hline Myocardial infarction & $36(7.7 \%)$ \\
\hline Congestive heart failure & $68(14.5 \%)$ \\
\hline Dementia & $66(14.0 \%)$ \\
\hline Chronic obstructive lung disease & $49(10.4 \%)$ \\
\hline Liver cirrhosis & $17(3.6 \%)$ \\
\hline Chronic kidney disease (creatinine > 2) & $64(13.6 \%)$ \\
\hline Hemodialysis use & $22(4.7 \%)$ \\
\hline Cancer & $85(18.1 \%)$ \\
\hline Obesity (BMI $\geq 30$ ) & $194(41.3 \%)$ \\
\hline Morbid obesity (BMI $\geq 35$ ) & $72(15.3 \%)$ \\
\hline $\begin{array}{l}\text { Charlson Comorbidity Index, median } \\
\text { (range) }\end{array}$ & $4(0-14)$ \\
\hline
\end{tabular}

Table 2 Clinical Measures at the Time of Admission for COVID-19. $S D$, standard deviation

\begin{tabular}{|c|c|}
\hline Clinical characteristics & Total cohort $(N=470)$ \\
\hline Febrile (temperature $\left.>38.0^{\circ} \mathrm{C}\right), n(\%)$ & $197(41.9 \%)$ \\
\hline Requiring supplemental oxygen, $n(\%)$ & $285(60.6 \%)$ \\
\hline Normal C-reactive protein, $n(\%)$ & \\
\hline$\leq 10 \mathrm{mg} / \mathrm{L}$ & $38(8.1 \%)$ \\
\hline C-reactive protein, mean $\mathrm{mg} / \mathrm{L}$ (SD) & \\
\hline 1st tertile & $23.6(15.7)$ \\
\hline 2nd tertile & $85.4(21.4)$ \\
\hline 3rd tertile & $197(54.7)$ \\
\hline Missing, $n(\%)$ & $38(8.1 \%)$ \\
\hline Normal ferritin, $n(\%)$ & \\
\hline$\leq 150 \mu \mathrm{g} / \mathrm{L}$ & $68(14.5 \%)$ \\
\hline Ferritin, mean $\mu \mathrm{g} / \mathrm{L}(\mathrm{SD})$ & \\
\hline 1st tertile & $164.8(94.7)$ \\
\hline 2nd tertile & $553.2(144.4)$ \\
\hline 3rd tertile & $2753.0(5588.7)$ \\
\hline Missing, $n(\%)$ & $50(10.6 \%)$ \\
\hline $\begin{array}{l}\text { Normal lactate dehydrogenase, } n(\%) \\
\leq 250\end{array}$ & $136(28.9 \%)$ \\
\hline Lactate dehydrogenase, mean U/L (SD) & \\
\hline 1st tertile & $206.5(36.6)$ \\
\hline 2nd tertile & $320.4(36.7)$ \\
\hline 3rd tertile & $562.0(254.60)$ \\
\hline Missing & $20(4.3 \%)$ \\
\hline Normal D-dimer, $n(\%)$ & \\
\hline$\leq 500 \mathrm{ng} / \mathrm{mL}$ & $55(11.7 \%)$ \\
\hline D-dimer, mean ng/mL (SD) & \\
\hline 1st tertile & $558.5(217.6)$ \\
\hline 2nd tertile & $1260.3(220.3)$ \\
\hline 3rd tertile & $3579.1(2190.4)$ \\
\hline Missing & $33(7.0 \%)$ \\
\hline Absolute lymphocyte count, mean (SD) & $1.3(5.8)$ \\
\hline Code status on admission & \\
\hline Full code & $393(83.6 \%)$ \\
\hline Do not resuscitate & $14(3.0 \%)$ \\
\hline Do not intubate & $4(0.9 \%)$ \\
\hline Do not resuscitate and do not intubate & $59(12.5 \%)$ \\
\hline
\end{tabular}

\section{Clinical Measures and Outcomes for Hospitalized Patients with COVID-19}

Table 3 depicts the clinical measures and outcomes for patients hospitalized with COVID-19 by survival status (alive vs. deceased). Overall, $194(41.3 \%)$ of patients received hydroxychloroquine, $106(22.6 \%)$ received remdesivir, 52 $(11.1 \%)$ received corticosteroids, and $21(4.5 \%)$ received tocilizumab. Deceased patients had higher inflammatory markers during admission and lower absolute lymphocyte count compared to those discharged alive (Table 3).

The median hospital LOS for the entire cohort was 8 days (IQR 1-37). Overall, 178 (37.9\%) patients were admitted to the ICU, $158(33.6 \%)$ received mechanical ventilation, 138 (29.4\%) received vasopressors, and $118(25.1 \%)$ died during hospitalization. When excluding patients who had documented limitation of life-sustaining therapies on admission, $21.1 \%$ (83/393) patients died during hospitalization. The mortality rate was higher for men and for higher age groups, as depicted in Figure 1. Overall, 22.3\% (105/470) had a palliative care consultation. Among those who died during admission $(n$ $=118), 65(55.1 \%)$ received a palliative care consultation with a median time from palliative care consultation to death of 4 days (IQR 1-20). Additionally, 143 (30.4\%) patients had orders to limit life-sustaining treatments such as resuscitation 
Table 3 Clinical Measures and Outcomes of Patients Alive and Deceased. $S D$, standard deviation; $C R P, C$-reactive protein; $L D H$, lactate dehydrogenase; $I C U$, intensive care unit

\begin{tabular}{|c|c|c|c|}
\hline & $\begin{array}{l}\text { Patients } \\
\text { alive } \\
(N=352)\end{array}$ & $\begin{array}{l}\text { Patients } \\
\text { deceased } \\
(N=118)\end{array}$ & $\begin{array}{l}\text { Total } \\
\text { cohort } \\
(N=470)\end{array}$ \\
\hline \multicolumn{4}{|l|}{ Clinical measures } \\
\hline $\begin{array}{l}\text { Highest temperature, } \\
\text { mean (SD) }\end{array}$ & $38.5(0.9)$ & $38.8(1.0)$ & $38.6(0.9)$ \\
\hline Lowest ALC, mean (SD) & $0.79(0.66)$ & $0.57(0.89)$ & $\begin{array}{l}0.74 \\
(0.73)\end{array}$ \\
\hline \multicolumn{4}{|c|}{ Inflammatory markers, mean (SD) } \\
\hline Highest CRP $(\mathrm{mg} / \mathrm{L})$ & $\begin{array}{l}138.9 \\
(94.9)\end{array}$ & $221.7(95.5)$ & $\begin{array}{l}158.6 \\
(101.6)\end{array}$ \\
\hline Highest Ferritin $(\mu \mathrm{g} / \mathrm{L})$ & $\begin{array}{l}1593 \\
(4247.3)\end{array}$ & $\begin{array}{l}2865 \\
(7746.1)\end{array}$ & $\begin{array}{l}1919.9 \\
(5395.2)\end{array}$ \\
\hline Highest LDH (U/L) & $\begin{array}{l}436.6 \\
(511.7)\end{array}$ & $\begin{array}{l}659.2 \\
(1440.2)\end{array}$ & $\begin{array}{l}490.9 \\
(842.4)\end{array}$ \\
\hline $\begin{array}{l}\text { Highest D-dimer (ng/ } \\
\mathrm{mL} \text { ) }\end{array}$ & $\begin{array}{l}2469.7 \\
(2156.7)\end{array}$ & $\begin{array}{l}3826.5 \\
(2628.8)\end{array}$ & $\begin{array}{l}2809.7 \\
(2355.8)\end{array}$ \\
\hline \multicolumn{4}{|l|}{ Treatments used, $n(\%)$} \\
\hline Corticosteroids & $35(9.9 \%)$ & $17(14.4 \%)$ & $\begin{array}{l}52 \\
(11.1 \%)\end{array}$ \\
\hline Tocilizumab & $13(3.7 \%)$ & $8(6.8 \%)$ & $21(4.5 \%)$ \\
\hline Remdesivir & $86(24.4 \%)$ & $20(16.9 \%)$ & $\begin{array}{l}106 \\
(22.6 \%)\end{array}$ \\
\hline Hydroxychloroquine & $\begin{array}{l}144 \\
(40.9 \%)\end{array}$ & $50(42.4 \%)$ & $\begin{array}{l}194 \\
(41.3 \%)\end{array}$ \\
\hline $\begin{array}{l}\text { Palliative care } \\
\text { consultation, } n(\%)\end{array}$ & $40(11.4 \%)$ & $65(55.1 \%)$ & $\begin{array}{l}105 \\
(22.3 \%)\end{array}$ \\
\hline \multicolumn{4}{|l|}{ Outcome measures, $n(\%)$} \\
\hline $\begin{array}{l}\text { Orders to limit life- } \\
\text { sustaining treatments }\end{array}$ & $34(9.7 \%)$ & $109(92.4 \%)$ & $\begin{array}{l}143 \\
(30.4 \%)\end{array}$ \\
\hline ICU admission & $\begin{array}{l}104 \\
(29.6 \%)\end{array}$ & $74(62.7 \%)$ & $\begin{array}{l}178 \\
(37.9 \%)\end{array}$ \\
\hline Mechanical ventilation & $85(24.1 \%)$ & $73(61.9 \%)$ & $\begin{array}{l}158 \\
(33.6 \%)\end{array}$ \\
\hline $\begin{array}{l}\text { Hospital LOS, median } \\
\text { (IQR) }\end{array}$ & $8.0(1-37)$ & $8.0(1-29)$ & $8.0(1-37)$ \\
\hline
\end{tabular}

and intubation. Moreover, 104 patients $(22.1 \%)$ transitioned to Comfort Measures Only during their hospitalization. Among the deceased cohort, the median time from code status change to death was 1 day (IQR 1-9). Among those discharged alive, the majority $(59.1 \%)$ were discharged home, $23.3 \%$ were discharged to a rehab facility, and $15.5 \%$ were discharged to a skilled nursing facility. Overall, 8.1\% (38/470) of our cohort experienced a hospital readmission.

\section{Clinical Measures and Outcomes of Patients Admitted to the ICU Due to COVID-19}

Among patients admitted to the ICU $(N=178), 150$ $(84.3 \%)$ received mechanical ventilation, $138(77.5 \%)$ received vasopressors, $17(9.5 \%)$ received renal replacement therapy, and $4(2.3 \%)$ received ECMO (Table 4$)$. The median time on the ventilator was 10 days (IQR 1-29). The mean $\mathrm{PaO}_{2} / \mathrm{F}$ ratio was 171.9 ( $\left.\mathrm{SD}=73.5\right)$. Overall, 178 patients $(58.4 \%)$ were discharged from the hospital alive $(58.4 \%, 104 / 178)$. Of note, 11 patients $(6.2 \%)$ received cardiopulmonary resuscitation (CPR) with one patient surviving to hospital discharge. Palliative care was consulted for 59 ICU patients $(33.1 \%)$ and 81 ICU patients $(45.5 \%)$ had orders to limit life-sustaining treatments such as resuscitation and intubation. Moreover, 64 patients $(35.9 \%)$ transitioned to Comfort Measures Only during their ICU stay.

\section{Factors Associated with Mortality During Hospitalization for COVID-19}

In unadjusted analyses, older age, White race, history of statin use, history of angiotensin-converting enzyme inhibitors or angiotensin II receptor blockers use, higher comorbidity score, the use of supplemental oxygen on admission, and higher inflammatory markers on admission were all associated with higher odds of mortality (Table 5).

In the multivariate logistic regression analyses $(n=420)$ (Table 5), older age $(\mathrm{OR}=1.04$, [95\% CI 1.02,1.07], $P<0.001)$, male sex $(\mathrm{OR}=2.14$, [95\% CI 1.23, 3.75], $P=0.007)$, higher comorbidity score $(\mathrm{OR}=1.20$, [95\% CI 1.07, 1.34], $P=0.001)$, the use of supplemental oxygen on admission (OR $=1.20,[95 \%$ CI 1.07, 1.34], $P=0.001)$, and elevated lactate dehydrogenase

\section{Mortality by Age Group and Sex}

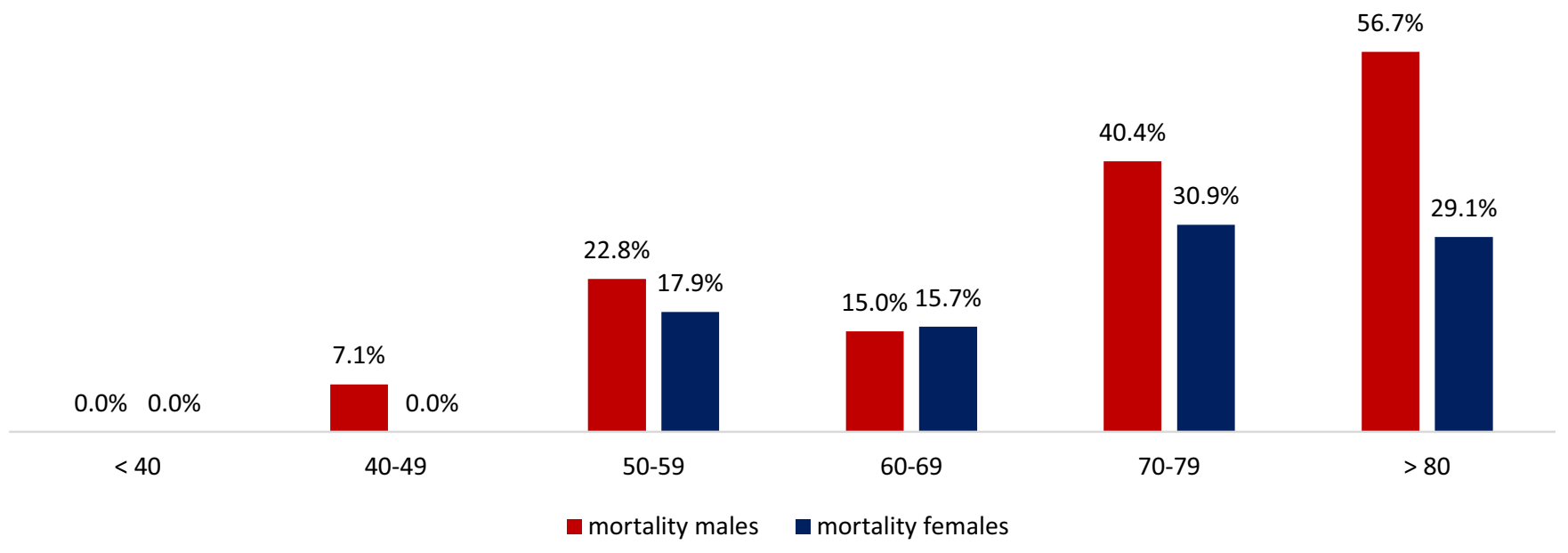

Figure 1 Mortality rates by age group and sex. 
Table 4 Clinical Measures and Outcomes of Patients Admitted to the Intensive Care Unit Due to COVID-19. SD, standard deviation; $I C U$, intensive care unit; $C V V H$, continuous veno-venous hemofiltration; $\mathrm{ECMO}$, extracorporeal membrane oxygenation; $\mathrm{FIO}_{2}$, fraction of inspired oxygen; $C P R$, cardiopulmonary resuscitation

\begin{tabular}{|c|c|}
\hline Clinical measures and outcomes & $\begin{array}{l}\text { Patients admitted to } \\
\text { ICU }(N=178)\end{array}$ \\
\hline $\begin{array}{l}\text { Mechanical ventilation, } n(\%) \\
\text { Days on the ventilator, median (IQR) } \\
\text { ICU length of stay, median (IQR) } \\
\mathrm{PaO}_{2} / \mathrm{FIO}_{2} \text { ratio, mean (SD) } \\
\text { Receipt of vasopressors, } n(\%) \\
\text { CVVH, } n(\%) \\
\text { ECMO, } n(\%) \\
\mathrm{CPR}, n(\%) \\
\text { Palliative care consultation, } n(\%) \\
\text { Orders to limit life-sustaining treatments, } n(\%) \\
\text { Discharged alive, } n(\%)\end{array}$ & $\begin{array}{l}150(84.3 \%) \\
10.0(1-29) \\
10.0(1-34) \\
171.8(73.5) \\
138(77.5 \%) \\
17(9.6 \%) \\
4(2.3 \%) \\
11(6.2 \%) \\
59(33.1 \%) \\
81(45.5 \%) \\
104(58.4 \%)\end{array}$ \\
\hline
\end{tabular}

(compared to 1st tertile, 2nd tertile OR $=4.07$, [95\% CI 1.91, 8.69], $P<0.001$; 3rd tertile: OR $=8.04$, [95\% CI 3.59], 18.0, $P<$ 0.001 ) were all associated with higher mortality among patients hospitalized for COVID-19. We conducted sensitivity analyses incorporating the other inflammatory markers (C-reactive protein, ferritin, and D-dimer) in separate multivariate regression models and obtained similar results. We also conducted a sensitivity analysis excluding patients who had limitations on lifesustaining therapies on admission to the hospital and obtained similar results in our multivariate regression model (Supplemental Table 1).

\section{DISCUSSION}

In this study, we demonstrate that the majority of hospitalized patients with COVID-19 and even the majority of those who received mechanical ventilation survived to hospital discharge. Mortality rates were $25 \%$, markedly lower than those previously reported. Hospital LOS and days on ventilator were approximately 5-6 longer than prior reports. Age, male sex, Charlson Comorbidity Index score, inflammatory markers, and supplemental oxygen use on admission were all associated with mortality.

The surge in hospital utilization due to COVID-19 is unprecedented in the modern era. ${ }^{15}$ Health systems have had to rapidly re-organize in-patient services and expand ICU capacity. Initial studies from cities overwhelmed by COVID-19 patients described exceptionally high mortality rates. ${ }^{4,7}$ The more favorable outcomes we report likely reflect COVID-19 outcomes in a health system that was not tested to the point of critical resource scarcity.

When health systems are not overwhelmed and patients can remain hospitalized or on ventilators for prolonged periods, outcomes are not as poor. It is important to note that a substantial number of patients in prior reports were still hospitalized and this may have inflated mortality rates for patients receiving ICU care. Nonetheless, $25 \%$ of the patients hospitalized with COVID-19 and over $40 \%$ of those admitted to the ICU died during their hospitalization, underscoring the gravity of this illness. These

Table 5 Unadjusted and Multivariate Logistic Regression Examining Factors Associated with Mortality in Hospitalized Patients with COVID19. $C I$, confidence interval; $A C E-I$, angiotensin-converting enzyme inhibitor; $A R B$, angiotensin receptor blocker; $B M I$, body mass index; $N S A I D$, non-steroidal anti-inflammatory drugs; $L D H$, lactate dehydrogenase; $C R P$, C-reactive protein

\begin{tabular}{|c|c|c|c|c|}
\hline \multirow[t]{2}{*}{ Factors } & \multicolumn{2}{|l|}{ Unadjusted analyses } & \multicolumn{2}{|c|}{ Multivariate logistic model } \\
\hline & Odds ratio $(95 \% \mathrm{CI})$ & $P$ value & Odds ratio $(95 \% \mathrm{CI})$ & $P$ value \\
\hline Age (years) & $1.05(1.03,1.07)$ & $<0.001$ & $1.04(1.02,1.07)$ & $<0.001$ \\
\hline Male sex & $1.77(1.15,2.72)$ & 0.009 & $2.14(1.23,3.75)$ & 0.007 \\
\hline White race & $1.57(1.03,2.39)$ & 0.035 & $1.54(0.84,2.81)$ & 0.160 \\
\hline Hispanic ethnicity & $0.67(0.43,1.05)$ & 0.082 & $1.03(0.55,1.93)$ & 0.921 \\
\hline Obese BMI & $1.06(0.69,1.62)$ & 0.780 & & \\
\hline Charlson Comorbidity Index score & $1.28(1.19,1.37)$ & $<0.001$ & $1.20(1.07,1.34)$ & 0.001 \\
\hline History of statin use & $2.01(1.31,3.08)$ & 0.001 & $0.96(0.54,1.70)$ & 0.898 \\
\hline History of ACE-I/ARB use & $1.70(1.10,2.62)$ & 0.016 & $1.64(0.94,2.86)$ & 0.080 \\
\hline History of NSAID use & $1.11(0.70,1.76)$ & 0.654 & & \\
\hline History of corticosteroid use & $1.68(0.89,3.15)$ & 0.105 & & \\
\hline History of smoking & $1.51(0.98,2.32)$ & 0.058 & $1.07(0.61,1.88)$ & 0.814 \\
\hline Supplemental oxygen on admission & $3.52(2.13,5.81)$ & $<0.001$ & $2.17(1.17,4.03)$ & 0.014 \\
\hline \multicolumn{5}{|l|}{ LDH on admission } \\
\hline 1st tertile & Ref & & Ref & \\
\hline 2nd tertile & $2.02(1.09,3.73)$ & 0.025 & $4.07(1.91,8.69)$ & $<0.001$ \\
\hline 3rd tertile & $3.99(2.22,7.16)$ & $<0.001$ & $8.04(3.59,18.0)$ & $<0.001$ \\
\hline \multicolumn{5}{|l|}{ CRP on admission } \\
\hline 1 st tertile & Ref & & & \\
\hline 2nd tertile & $1.95(1.07,3.54)$ & 0.028 & & \\
\hline 3rd tertile & $2.84(1.59,5.06)$ & $<0.001$ & & \\
\hline \multicolumn{5}{|l|}{ Ferritin on admission } \\
\hline $1 \mathrm{st}$ tertile & Ref & & & \\
\hline 2nd tertile & $1.21(0.69,2.09)$ & 0.505 & & \\
\hline 3rd tertile & $1.47(0.85,2.52)$ & 0.162 & & \\
\hline \multicolumn{5}{|l|}{ D-Dimer on admission } \\
\hline 1 st tertile & Ref & & & \\
\hline 2nd tertile & $3.60(1.95,6.65)$ & $<0.001$ & & \\
\hline 3rd tertile & $3.63(1.97,6.72)$ & $<0.001$ & & \\
\hline Treatment with remdesivir & $0.63(0.36,1.08)$ & 0.094 & $0.70(0.35,1.40)$ & 0.315 \\
\hline Treatment with hydroxychloroquine & $1.06(0.69,1.62)$ & 0.780 & & \\
\hline
\end{tabular}

Bold indicate statistically significant findings 
results have large macro-policy implications for emergency preparedness as the USA considers preparations for subsequent waves of COVID-19 and other pandemics. Even in areas experiencing a high volume of COVID-19 cases, ensuring that there are adequate resources to meet the potential demand for medical resources is of foremost importance to the national response to COVID-19. ${ }^{16,17}$

These mortality rates have significant implications for patient and family decision-making. ACP and decision-making for serious illness more broadly relies on accurate information about the risks and benefits of life-prolonging interventions and the likely disposition. ${ }^{9,10,18}$ Early reported mortality rates for COVID-19 were quite high, which may have led to ACP discussions and decisions that were not fully informed. The present study serves as a more accurate portrayal of survival with COVID-19 in a busy health system with a surge of patients and hopefully leads to more informed decision-making. It is important to note that most patients in our cohort did not have any limitations on lifesustaining therapies at the time of admission to the hospital, despite their older age and multiple comorbid conditions. Unfortunately, this likely reflects the lack of adequate ACP discussions and automatic "full code" status often employed in the USA compared to other countries. ${ }^{19}$ Nonetheless, ACP discussions are critical to ensure patients make informed decisions regarding their medical care.

There was extensive use of palliative care services in the ICU. Given the critical role palliative care can play in helping patients and families make informed decisions about their care, ${ }^{8,20,21}$ the existing national shortage of palliative care clinicians is an urgent crisis and rivals other needs such as personal protective equipment and nasal swabs. $^{22-26}$ Exploring goals of care, coordinating and effectuating patient preferences, and controlling pain and suffering are of paramount importance in the face of an uncertain illness such as COVID-19. ${ }^{27,}{ }^{28}$ Significantly expanding the clinician workforce with these skills and rapidly disseminating tools to support ACP is vital. Earlier ACP may also help ease the burden of limited in-patient palliative care resources downstream. ${ }^{27-29}$

This study has several notable limitations and numerous strengths. First, while the study population was diverse with more than half being non-White, the cohort is from a single metropolitan area, thereby limiting the generalizability of our findings. Second, 91 patients remained hospitalized and their outcome data were absent from our analyses. We excluded these patients since Boston hospitals experienced crisis of COVID-19 cases by the end of April and our goal was to report on patient outcomes in hospitals not experiencing crisis. Prior studies in the USA had largely incomplete data sets. Nonetheless, excluding patients who remained hospitalized may result in a selection bias as those who remained hospitalized may have different outcomes compared to the study cohort. Third, knowledge and practices regarding COVID-19 treatment are rapidly changing and this data set reflects the early period of COVID-19 in the USA. It is possible that mortality rates change over time due to identification of effective treatments. Fourth, there was limited follow-up; longer term sequelae remain unclear. Fourth, data regarding race was obtained from the EHR, which includes an "other" category that is not fully explained, which limits our ability to interpret data on outcomes of patients based on race. Fifth, while our multivariate logistic regression model adjusted for factors such as comorbidities and severity of illness at presentation, it is possible that there are other unmeasured confounders that may affect the relationship between treatment received and risk of mortality. Additionally, we utilized a $P<0.10$ as a cut-off in our multivariable analysis modeling approach, which may have also omitted potential confounders. Finally, this study included only hospitalized patients with confirmed COVID-19. Patients who did not present to the hospital and died at home, or were discharged to hospice from the emergency department are not included. Prior studies also had similar limitations.

Managing the COVID-19 global pandemic involves ensuring that health systems are not overwhelmed. This study was conducted in a region of the USA that did not experience crisis standards and exhibited a much lower rate of hospital mortality than in prior papers which reported data from areas enduring critical shortages. Protecting health systems so they will not be over-run and surpass the surge capacity for medical resources such as ICU beds, ventilators, and appropriately trained medical staff have a salutary effect on prognosis and survival.

Corresponding Author: Areej El-Jawahri, MD; Department of Hematology Oncology, Massachusetts General Hospital, Boston, MA, USA (e-mail: ael-jawahri@partners.org).

Supplementary Information The online version contains supplementary material available at https://doi.org/10.1007/s11606-02106622-x.

Author Contributions Drs. El-Jawahri and Volandes had full access to all of the data in the study and take responsibility for the integrity of the data and the accuracy of the data analysis.

Study concept and design: El-Jawahri, Bohossian, Paasche-Orlow, Lakin, Cooper, and Volandes

Acquisition of data: El-Jawahri, Bohossian, Lakin, Johnson, Jagielo, Brannen, Reynolds, Coogan, and Vaughn

Analysis and interpretation of data: El-Jawahri, Bohossian, PaascheOrlow, Lakin, Johnson, Cooper, Jagielo, Brannen, Reynolds, Coogan, Vaughn, and Volandes

Drafting of the manuscript: El-Jawahri, Paasche-Orlow, and Volandes Critical revision of the manuscript for important intellectual content: El-Jawahri, Bohossian, Paasche-Orlow, Lakin, Johnson, Cooper, Jagielo, Brannen, Reynolds, Coogan, Vaughn, and Volandes

Statistical analysis: El-Jawahri and Volandes

Obtained funding: Not applicable

Administrative, technical, or material support: El-Jawahri and Volandes

Study supervision: El-Jawahri and Volandes

Funding Drs. El-Jawahri, Paasche-Orlow, Lakin, and Volandes are supported by the NIH Collaboratory fund NIA UH3 AG060626-02. Dr. El-Jawahri is a Scholar in Clinical Research for the Lymphoma and Leukemia Society. 


\section{Declarations:}

Conflict of Interest: All authors have completed and submitted the ICMJE FORM for disclosure of potential conflicts of interest.

Financial Disclosures: Research reported in this publication was supported within the National Institutes of Health (NIH) Health Care Systems Research Collaboratory by cooperative agreement UH3AG060626 from the National Institute on Aging. This work also received logistical and technical support from the NIH Collaboratory Coordinating Center through cooperative agreement U24ATO09676. The content is solely the responsibility of the authors and does not necessarily represent the official views of the National Institutes of Health.

Role of the Sponsor: None of the sponsors had any role in the design and conduct of the study; collection, management, analysis, and interpretation of the data; and preparation or approval of the manuscript.

\section{REFERENCES}

1. Holshue ML, DeBolt C, Lindquist S, et al. First Case of 2019 Novel Coronavirus in the United States. N Engl J Med. 2020;382:929-36.

2. Coronavirus disease 2019 (COVID-19): cases in US. 2020. (Accessed April 20th, 2020, at https://www.cdc.gov/coronavirus/2019-ncov/ cases-updates/cases-in-us.html.)

3. Zhou F, Yu T, Du R, et al. Clinical course and risk factors for mortality of adult inpatients with COVID-19 in Wuhan, China: a retrospective cohort study. Lancet. 2020;395:1054-62.

4. Grasselli G, Pesenti A, Cecconi M. Critical care utilization for the COVID-19 outbreak in Lombardy, Italy: early experience and forecast during an emergency response. JAMA. 2020;323:1545-46.

5. Guan WJ, Ni ZY, Hu Y, et al. Clinical Characteristics of Coronavirus Disease 2019 in China. N Engl J Med. 2020;382:1708-20.

6. Huang $\mathbf{C}$, Wang $\mathbf{Y}, \mathbf{L i} \mathbf{X}$, et al. Clinical features of patients infected with 2019 novel coronavirus in Wuhan, China. Lancet. 2020;395:497-506.

7. Richardson S, Hirsch JS, Narasimhan M, et al. Presenting characteristics, comorbidities, and outcomes among 5700 patients hospitalized with COVID-19 in the New York City area. JAMA. 2020;323:2052-59.

8. Institute of Medicine. Dying in America, Improving Quality and Honoring Individual Preferences Near the End of Life. Washington, DC: The National Academies Press; 2014.

9. Rietjens JAC, Sudore RL, Connolly M, et al. Definition and recom mendations for advance care planning: an international consensus supported by the European Association for Palliative Care. Lancet Oncol. 2017;18:e543-e51

10. Sudore RL, Heyland DK, Lum HD, et al. Outcomes That Define Successful Advance Care Planning: A Delphi Panel Consensus. J Pain Symptom Manag 2018;55:245-55.e8.

11. Charlson ME, Pompei P, Ales KL, MacKenzie CR. A new method of classifying prognostic comorbidity in longitudinal studies: development and validation. J Chronic Dis. 1987;40:373-83.
12. Bursac Z, Gauss CH, Williams DK, Hosmer DW. Purposeful selection of variables in logistic regression. Source Code Biol Med. 2008:3:17.

13. Bendel RB, Afifi AA. Comparison of stopping rules in forward regression. J Am Stat Assoc. 1977;72:46-53.

14. Mickey J, Greenland S. A study of the impact of confounder-selection criteria on effect estimation. Am J Epidemiol. 1989;129:125-37.

15. Moghadas SM, Shoukat A, Fitzpatrick MC, et al. Projecting hospital utilization during the COVID-19 outbreaks in the United States. Proc Natl Acad Sci U S A. 2020;117:9122-6.

16. Oh J, Lee JK, Schwarz D, Ratcliffe HL, Markuns JF, Hirschhorn LR National Response to COVID-19 in the Republic of Korea and Lessons Learned for Other Countries. Health Syst Reform. 2020;6:e1753464.

17. Gostin LO, Hodge JG Jr, Wiley LF. Presidential Powers and Response to COVID-19. JAMA. 2020

18. Sudore RL, Fried TR. Redefining the "planning" in advance care planning: preparing for end-of-life decision making. Ann Intern Med 2010; 153:256-61.

19. Yadav KN, Gabler NB, Cooney E, et al. Approximately One In Three US Adults Completes Any Type Of Advance Directive For End-Of-Life Care. Health Aff. 2017;36:1244-51.

20. Smith TJ, Temin S, Alesi ER, et al. American Society of Clinical Oncology provisional clinical opinion: the integration of palliative care into standard oncology care. J Clin Oncol. 2012;30:880-7.

21. Schnipper LE, Smith TJ, Raghavan D, et al. American Society of Clinical Oncology identifies five key opportunities to improve care and reduce costs: the top five list for oncology. J Clin Oncol. 2012;30:1715-24.

22. Dumanovsky T, Augustin R, Rogers M, Lettang $\mathbf{K}$, Meier DE, Morrison RS. The Growth of Palliative Care in U.S. Hospitals: A Status Report. J Palliat Med. 2016;19:8-15.

23. Dumanovsky T, Rogers M, Spragens LH, Morrison RS, Meier DE Impact of Staffing on Access to Palliative Care in U.S. Hospitals. J Palliat Med. 2015;18:998-9.

24. Hua M, Ma X, Morrison RS, Li G, Wunsch H. Association between the Availability of Hospital-based Palliative Care and Treatment Intensity for Critically Ill Patients. Ann Am Thorac Soc. 2018;15:1067-74.

25. Rush B, Berger L, Anthony Celi L. Access to Palliative Care for Patients Undergoing Mechanical Ventilation With Idiopathic Pulmonary Fibrosis in the United States. Am J Hosp Palliat Care. 2018;35:492-6.

26. Sullivan KM, Witherspoon RP, Storb R, et al. Alternating-day cyclosporine and prednisone for treatment of high-risk chronic graft-v-host disease. Blood. 1988;72:555-61

27. The L. Palliative care and the COVID-19 pandemic. Lancet 2020;395:1168

28. Chidiac C, Feuer D, Naismith J, Flatley M, Preston N. Emergency palliative care planning and support in a COVID-19 pandemic. J Palliat Med. 2020;23:752-3.

29. Etkind SN, Bone $\mathbf{A E}$, Lovell $\mathbf{N}$, et al. The role and response of palliative care and hospice services in epidemics and pandemics: a rapid review to inform practice during the COVID-19 pandemic. J Pain Symptom Manag. 2020;60:e31-e40.

Publisher's Note: Springer Nature remains neutral with regard to jurisdictional claims in published maps and institutional affiliations. 